\title{
Ortodontide Kullanılan Şeffaf Plakların Su Emilimlerinin ve Renklenmelerinin Değerlendirmesi
}

\author{
Duygu ERGEL*, Sanaz SADRY ${ }^{* *}$, Ufuk OK ${ }^{* * *}$
}

\section{$\ddot{O} \mathbf{z}$}

Amaç: Şeffaf plak kullanan hastalarda termoplastik malzemede oluşabilecek renk değişikliklerini önlemek amacıyla, hastalara su hariç her yiyecek ve içecek tüketimleri sırasında plaklarını çıkarmaları önerilmektedir. Ancak yine de günlük hayatta bazı hastalar, özellikle içecek tüketimi sırasında plaklarını çıkarmadan günlük rutinlerine devam etmektedir. Bu durumda termoplastik olan şeffaf plakların fiziksel özelliklerini etkilemektedir. Termoplastik malzemelerinin fiziksel özellikleriyle ilgili çok az çalışma vardır. Hastaların bilgilendirmesi açısından literatürde yeterli sayıda yol gösterici kanıtlar bulunmamaktadır. Bu çalışmada amaç, şeffaf plakların boyar ajanlara maruz bırakıldıktan sonra oluşan renk değişikliklerinin karşlaş̧ırmalı olarak incelenmesidir.

Yöntem: Çalışmamızda; 2 farklı şeffaf plak çeşidi (Invisalign ve Essix) her bir grupta 5'er adet olacak şekilde siyah çay, kahve, kola, kırmızı şarap ve suda $37^{\circ}$ C'ye ayarlanmış etüvde 6 gün süre ile bekletilmiştir. Aynı zamanda plaklar termal siklusa maruz bırakılmış, öncesi ve sonrası ağırlıkları hassas terazi ile kayıt altına alınmıştır. Veriler SPSS programı ile değerlendirilmiştir.

Bulgular: Invisalign grubunda şarabın istatistiksel olarak anlamlı şekilde renklendiği kaydedilmiş, siyah çay, kola, su ve kahve ise anlamlı bir fark oluşturmamıştır. Essix grubunda ise; kahve ve şarap anlaml şekilde renklenmiş olup, siyah çay, su ve kolada anlamlı bir renk değişikliği göstermemiştir. Her iki grup birbirleri ile kıyaslandığında ise renklenme miktarlarında anlamlı bir fark görülmemiştir. Termal siklus kullanılarak yapılan 4 saatlik yaşlandırma sonucuna göre, Essix grubunda kütlesel olarak (gram) istatistiksel anlamlı bir fark tespit edilmemiştir. Invisalign grubunda ise (gram olarak) istatistiksel olarak anlamlı bir fark görülmüştür.

Sonuç: Invisalign grubunda Essix grubuna oranla daha çok renk değişikliği görülmüştür ve en etkili değişiklik kahve çözeltisinde kayıt altına alınmıştır. Aynı zamanda su emilimi Invisalign grubunda daha fazla gözlemlenmiştir. Çalışmamızın sonuçları tedavi öncesi hastalara bilgilendirme amaçlı paylaşılması yararlı olacaktır.

Anahtar Sözcükler: Şeffaf plaklar, renklenme, biyobozunma.

\section{Evaluation of Water Absorption and Color Stability of Clear Aligners Used in Orthodontics}

\begin{abstract}
Aim: Patients using clear aligners remove their plates during every food and beverage consumption, except water, in order to prevent color changes that may occur in the thermoplastic material. However, in daily life, some patients continue their daily routines without removing their aligners, especially during beverage consumption. In this case, it affects the physical properties of the thermoplastic clear aligners. There are very few studies on the physical properties of thermoplastic materials. There is not enough guiding evidence in

\footnotetext{
Özgün Araştırma Makalesi (Original Research Article)

Geliş / Received: 16.10 .2021 \& Kabul / Accepted: 03.11.2021

DOI: https://doi.org/10.38079/igusabder.1010796

* Diş Hekimi, E-posta: duygue1997@gmail.com ORCID https://orcid.org/oooo-0001-7861-0499

** Dr. Öğr. Üyesi, İstanbul Aydin Üniversitesi, Diş Hekimliği Fakültesi, Ortodonti Anabilim Dalı, İstanbul, Türkiye,

E-posta: sanazsadry@aydin.edu.tr ORCID https://orcid.org/o000-0002-2160-0908

${ }_{* * * *}$ Dr. Öğr. Üyesi, İstanbul Gelişim Üniversitesi, Diş Hekimliği Fakültesi, Ortodonti Anabilim Dalı, İstanbul, Türkiye,

E-posta: uok@gelisim.edu.tr ORCID https://orcid.org/o000-0002-2920-0351
} 
the literature in terms of informing patients. The aim of this study is to comparatively examine the color changes of clear aligners after exposure to staining agents.

Method: In our study; two different sets of clear aligners (Invisalign and Essix) were kept in an oven set at $37^{\circ} \mathrm{C}$ in black tea, coffee, cola, red wine and water for 6 days in each group with 5 specimens. Also, all specimens had thermal aging and values before and after were recorded with precision balance. Results were evaluated with SPSS software.

Results: In the Invisalign group, statistically significant coloration of wine was recorded, while black tea, cola, water and coffee did not make a significant difference. In the Essix group, coffee and wine were significantly colored, while black tea, water and cola did not show a significant color change. When both groups are compared with each other, there is no significant difference in the amount of coloration. Based on the 4-hour aging result using the thermal cycle, no statistically significant difference was found in the Essix group in terms of mass (gram). There was a statistically significant difference (in grams) in the Invisalign group.

Conclusion: As a result of the study, more color changes were observed in the Invisalign group compared to the Essix group, and the most effective change was recorded in the coffee solution. In addition, water absorption was observed more in the Invisalign group. It will be useful to share the results of our study with the patients before the treatment for informational purposes.

Keywords: Clear aligners, color changes, biodegradation.

\section{Giriş}

Yetişkin hastaların \%75’i estetik açıdan dişlerinin görünümünden rahatsız olmaktadır ${ }^{1}$. Ancak tedavi olan ergen ve yetişkin hasta sayısı arttıkça geleneksel sabit apareylerden daha rahat, günlük yaşamlarıyla uyumlu ve yaşam kalitelerinden ödün vermeyecek tedavi yöntemleri tercih sebebi olmaktadır.

$\mathrm{Bu}$ nedenle dişlerdeki çapraşıklıkları tedavi etmek için termoplastik şeffaf plaklar kullanılmaya başlanmıştır². Bu yöntem, 1990'lı yıllarda Zia Chishti isimli bir bilgisayar bilimcisi tarafından metal diş telleri yerine şeffaf plastik apareyler kullanılarak tasarlanmıştır³. Daha sonra çeşitli firmaların da bu yöntemi geliştirmesiyle modern ortodontide yerini almıştır. Sabit apareylere göre tedavinin ilk günlerinde daha az ağrı oluşturması, takılıp çıkarılabilir olması, periodontal açısından daha sağlıklı olmaları gibi avantajları yanında, yüksek maliyetle üretilmeleri, ağız sıvısından etkilenmeleri ve renklenmeleri gibi dezavantajları da mevcuttur ${ }^{2}$. Şeffaf plak ile tedavi iki başlık altında incelenebilir. İlki termoplastik materyallerden oluşan Essix sistemdir. Alçı modeller ve vakumlu plak basma makineleri kullanılarak hazırlanan sistemlerdir4. Günümüzde polyester, kopolyester, polikarbonat, termoplastik poliüretanlar ve polipropilenler şeffaf plakların üretiminde en çok kullanılan materyallerdir5.

İkinci yöntem olan Invisalign sistem ise hem bir marka hem de bir sistemin adıdır. Invisalign bir fikir olarak, 1997 yllında bilgisayar mühendisliği öğrencileri Zia Chisti ve Kelsey Wirth tarafından ortaya atılmıştır. Invisalign sisteminde; Essix sisteminin prensipleri ve CAD/CAM teknolojisini, laboratuvar teknikleriyle birleştirerek, dişleri hareket veren plaklar üretmişlerdir6.

Bu sistemde; hastadan alınan ölçüler ve kapanış kaydı, hekimi tarafından yapılan tedavi planı ile Invisalign laboratuvarına gönderilir ve alçı modeller elde edilir. Alçı modeller lazer tarayıcı ile taranıp 3 boyutlu dijital modeller elde edilir. Klinisyen onayından sonra her tedavi basamağı için stereolitografik (reçineyi ışıkla sertleştirerek çalışan bir 3 boyutlu yazıcı teknolojisi) modeller üzerinde şeffaf plak serileri üretilerek ortodontiste gönderilir7. 
Mevcut apareylerin çoğu modifiye edilmiş polietilen tereftalat glikoldür (PET-G), ancak polipropilen, polikarbonat, poliüretanlar, kopolyester gibi materyaller de kullanılmaktadır. Yapisal olarak, PET-G malzemeleri amorftur ve şeffaftırlar ${ }^{8}$. Polimer gurundaki serbest karboksil grupları su içerisindeki $\mathrm{H}$ iyonları ile etkileşime girer ve polimer materyali su absorbe eder, polimer şişmesi ve boyut değişikliği meydana gelir, omurga zinciri geri döndürülemez şekilde bozulur9. Şeffaf termoplastik apareylerin şeffaflı̆̆ ve renk stabilitesi, en önemli avantajları arasında yer aldığından hem hastalar hem de klinisyenler için önemli hususlardır. Bu yüzden Essix yöntemiyle üretilen şeffaf plaklarla, stereolitografik yöntemle üretilen Invisalign grubu şeffaf plaklar çalışmamıza dahil edilmiştir.

Çalışmamızda, tüketilen içeceklerin plaklar üzerinde oluşturduğu renklenmeyi farklı çözelti ortamları oluşturarak karşılaştırmak amaçlanmıştır. $\mathrm{Bu}$ nedenle, 6 günlük in-vitro renklendirmeden sonra çeşitli şeffaf plak numunelerinin zaman içinde renk kararlılı̆̆ı ve estetik özellikler açısından herhangi bir farklılık gösterip göstermedikleri karşılaştırılmıştır.

Dental materyallerde termal yaşlanma ile görülen fiziksel değişiklikler; renk değişimi, saydamlık kaybı, çatlak oluşumu, su emilimi, aşınma, direnç kaybı ve oksidasyondur ${ }^{10}$. Çalışmamızın diğer amacı da ă̆ız ortamındaki ısı değişiminin şeffaf plaklar üzerindeki yaşlanma etkisini ölçmektir.

\section{Gereç ve Yöntem}

Çalışmamızda; G8 Smart Force Aligner Aktivasyon tipi olan Invisalign (Align Tecnology Inc., CA, A.B.D.) ve Essix (termoplastik poliüretan, PVC) (Scheu-Dental, Almanya) grubu iki farklı tipteki şeffaf plak üretim tekniği renk değişimlerini değerlendirmek için plaklar, belirlenen çözeltilerde bekletilmiştir.

In-vitro ortamda hazırlanan alçı modeller ile vakumlu plak basma makinesi (Dentsply Raintree Essix, İndiana, A.B.D.) kullanılarak plaklar hazırlanmıştır (Resim 1A ve B). Invisalign grubundaki plaklar ise firmadan temin edilmiştir.

Resim 1. A) Isıtılmış plağın alçı modele vakumlanması, B) Plakların alçı modele göre $\quad$ basılmış hali
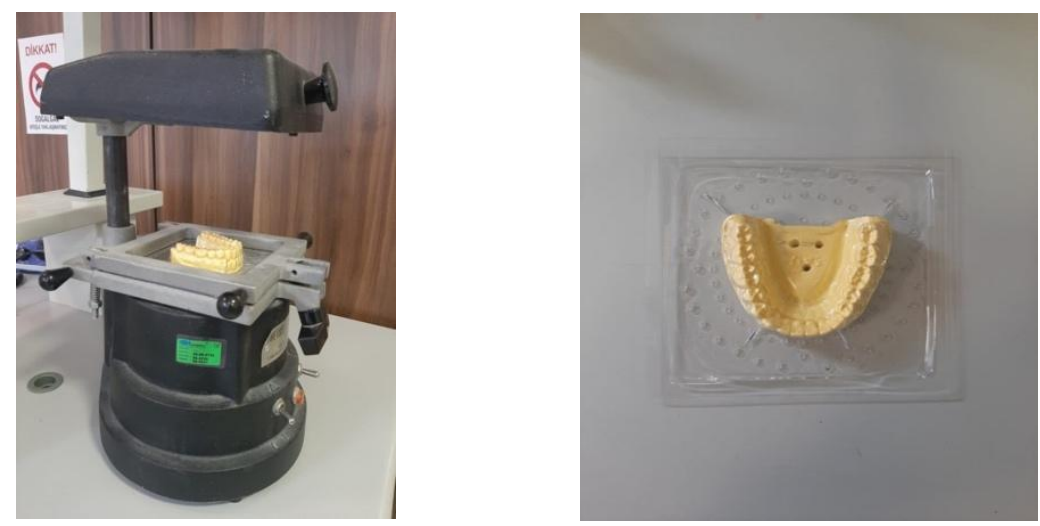

Plaklardaki renk değişikliği değerlendirmek amacıyla plakların ilk renk değerleri olan 1. ölçümler (To) spektrofotometre (Vita easyshade advance 4.0) ile ölçülmüştür. Her bir plağın ölçümü kaydedildikten, spektrofotometre kalibre edilmiştir. Ölçümler her bir plaktaki molar ve santral dişlerin gingival, orta üçlü ve insizal-oklüzal noktalarından (3 nokta ölçümü) yapılmıştır. Ölçümler her gün aynı saatte, aynı ışı altında, beyaz bir zemin üzerinde, optik sensor ucu her bir 
noktaya dik ve sıkı temas edecek şekilde tekrarlanmıştır. (Resim 2) Her nokta için M değerleri ve $\mathrm{L}, \mathrm{a}, \mathrm{b}$ değerleri istatistiksel değerlendirme için kaydedilmiştir.

Resim 2. Plakların ölçüm düzeneği

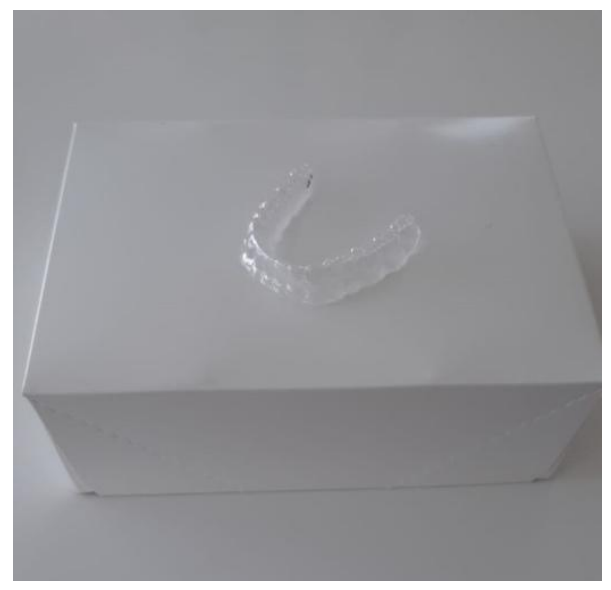

Çalışmamızda 25 tane Invisalign, 25 tane Essix olmak üzere toplam 50 adet şeffaf plak kullanılmıştır. Çalışmada renklendirme için 5 farklı düzenek kurulmuştur. Bu düzeneklerde çay, kahve, kola, kırmızı şarap ve distile su kullanılmıştır.

Çay grubu için 1 litre damıtılmış kaynar su içine 4 torba poşet çay (Yellow Label Tea; Lipton,

Hefei, Çin) kullanılmıştır ve 5 dakika bekletilmiştir. Kahve için 1 litre damıtılmış kaynar su ile 120-gram çözünebilir kahve tozu (Nescafe Orijinal, İsviçre) karıştırılmıştır. Diğer 3 düzenek için de kola (Coca-Cola, A.B.D.), kırmızı şarap (Buzbağ Bölge Serisi, Elâzı̆̆) ve distile su kullanılmıştır. Her iki grup için 5'er adet plak kullanılmıştır. Hazırlanan düzenek sıcaklığı $37^{\circ} \mathrm{C}$ de stabil tutmak için 6 gün süreyle (Şeffaf plaklar günde minimum 20-22 saat kullanma süresi önerilmektediri11,12. Ağız ortamında 1 haftalık renklendirme süresi plağın ağızda bulunmayan süresi ekarte edilerek 6 gün olarak belirlenmiştir) etüvde bekletilmiştir.

6. günün sonunda plaklar, çözeltilerden çıkarılıp distile su ile yıkanıp hava-su spreyi ile kurutulmuştur. Plakların renklenme sonrası ölçümünü ifade eden 2. Ölçümler (T1) aynı koşullarda To ölçümlerin yapıldığı noktalardan ölçülmüştür. Bulunan M değerleri ve L, a, b değerleri kaydedilmiştir.

\section{Renk Ölçümü}

Renk değişiklikleri $(\Delta \mathrm{E})$, Uluslararası Aydınlatma Komisyonu (CIE) $\mathrm{L} * \mathrm{a} * \mathrm{~b}$ * renk sistemi ile hesaplanmıştır ${ }^{13}$. $\mathrm{L}^{*}$, karanlıktan aydınlığa kadar parlaklığı gösterir (o ila 100, $\mathrm{O}=$ siyah ve $100=$ beyaz değerleri). $a^{*}$ ve $b^{*}$, renk bileşiklerini temsil eder. Pozitif $a^{*}$ kırmızıya karşlılk gelirken, negatif yeşil anlamına gelir. Pozitif $b^{*}$ sarıya karşıllı gelirken negatif mavidir. Toplam renk değişimi $(\Delta \mathrm{E})$ değeri, boyama öncesi ve sonrası renk farkını temsil eden $\Delta \mathrm{E}=\left[\left(\Delta \mathrm{L}^{*}\right) 2+\left(\Delta \mathrm{a}^{*}\right) 2\right.$ $+\left(\Delta \mathrm{b}^{*}\right)$ 2] $1 / 2$ denklemine göre hesaplanmıştır ve $\Delta \mathrm{L}^{*}, \Delta \mathrm{a}^{*}$ ve $\Delta \mathrm{b}^{*}(\mathrm{~T}=1,2)$, sirasıyla $\mathrm{L}^{*}, \mathrm{a}^{*}$ ve $\mathrm{b}^{*}$ renk parametrelerinin $\mathrm{T} 1$ - To arasındaki çıkarmalardır.

- To: boyama işleminden önce

- T1: bir boyama çözeltisine 6 gün maruz kaldıktan sonra 
Tablo 1. Ulusal standartlar derecelendirme tablosu'13

\begin{tabular}{|l|l|}
\hline Ulusal Standartlar Bürosu Birimleri & Renk Değişikliğinin Tanımı \\
\hline $0-0.5$ & İz: son derece hafif değişiklik \\
\hline $0.5-1.5$ & Hafif: hafif değişiklik \\
\hline $1.5-3.0$ & Fark edilebilir: algllanabilir \\
\hline 3.0-6.0 & Takdir edilebilir: belirgin değişiklik \\
\hline 6.0-12.0 & Çok: son derece belirgin değişiklik \\
\hline 12.0 ve daha fazlası & Çok fazla: diğer renge geçiş \\
\hline
\end{tabular}

\section{Termal Siklus}

Su emilimi, malzemede fiziksel ve kimyasal değişikliklere neden olarak, polimerin mekanik özelliklerinde geri dönüşü olmayan bir bozulmaya yol açar. Aynı zamanda ağızda, nem emiliminin ve genleşmenin neden olduğu boyut değişikliği, plağın uyumluğunu etkileyebilir ${ }^{14}$.

Her bir firmadan 5 adet olacak şekilde toplam 10 adet numune hazırlanmıştır. Plakların ağırlık farkını hesaplayabilmek için bekletme öncesi plakların gram cinsinden kütlesi hassas terazi ile ölçülüp kaydedilmiştir. Invisalign grubu plaklar için üretici tavsiyesi ve literatürde gerekli koşullarda 1 hafta kullanımının yeterli olduğu belirtilmiştir ${ }^{11,12,15}$. 1 haftalık yaşlandırma için plaklar 4 saat termal siklusta yaşlandırılmıştır. Termal siklus cihazı (Moddental, Ankara, Türkiye) $5-55^{\circ} \mathrm{C}$ ve bekleme süresi 5 saniye olacak şekilde 4 saat süreye ayarlanmıştır. (Resim 3 A ve B) 4 saatin sonunda hava ile kurutulan plakların kütleleri tekrar hassas terazi ile ölçülüp T1 ölçüm değerleri kaydedilmiştir.

Resim 3. A) Termal siklus cihazı B) Termal siklusun sıcak-soğuk hazne ayarı
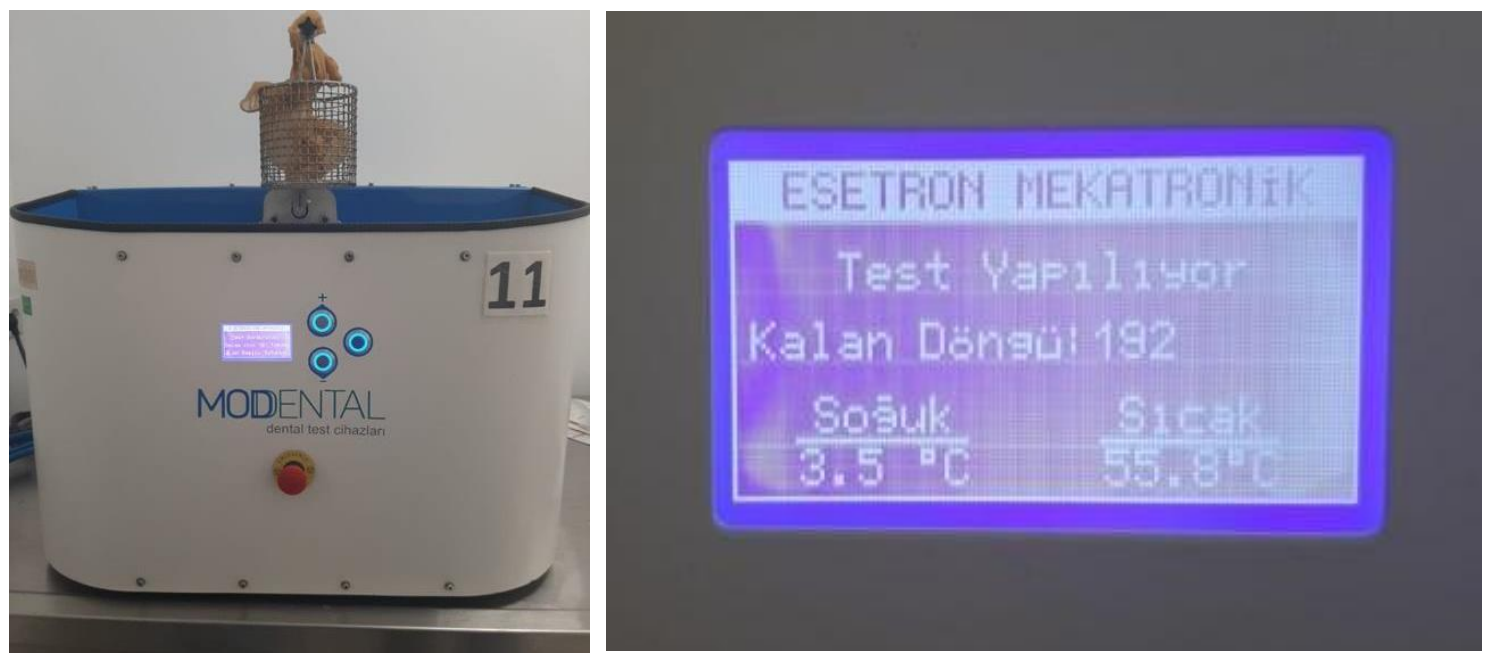

Ağırlıktaki artış yüzde (\%) olarak aşağıdaki gibi hesaplanmıştır:

[(Wt-Wo) / Wo] × 100 Burada Wt T1 zamanındaki (t) ağırlık ve Wo To zamanındaki ağırlıktır.

\section{Ístatistiksel Analiz}

Tüm veriler bilgisayarda SPSS (statistical package for social sciences) for Windows programma kaydedilerek analiz edilmiştir. Verilerin analizinde ilk olarak hangi testlerin 
(parametrik/nonparametrik testler) uygulanacağına karar vermek için karşılanması gereken varsayımlar test edilmiştir. Dağılımın normalliğine karar vermek için Shapiro-Wilk, normal dağılımın diğer varsayımları olan basıklık ve çarpıklık değerleri ve histogram grafiğinden yararlanılmıştır. Bağımsız iki grup karşılaştırmasında t-testi (Independent sample t-testi) ilişkisiz iki ya da daha fazla grupların karşılaştırılmasında tek yönlü varyans analizi ve farkın kaynağının belirlenmesi için post hoc testlerinden Boferroni testi kullanılmıştır. İlişkili iki grup arası farka Paired Sample t test ve Wilcoxon test ile bakılmıştır. Elde edilen değerlerin anlamlı olup olmadı̆̆ının yorumlanmasında 0.05 anlamlılık düzeyi ölçüt olarak kullanılmıştır.

\section{Bulgular}

Plakların renklenme miktarları arasındaki farka (delta e) ait veriler karşılaştırılmıştır. To ve T1 zamanlarında ilk ölçümden 6 gün sonra tekrar ölçülmüştür. Ölçümlerin fotoğrafları aşağıda gösterilmiştir (Resim 4 ve 5).

Resim 4. Essix marka plakların her bir çözeltide 6 gün boyunca boyanmadan önceki ve sonraki fotoğrafları

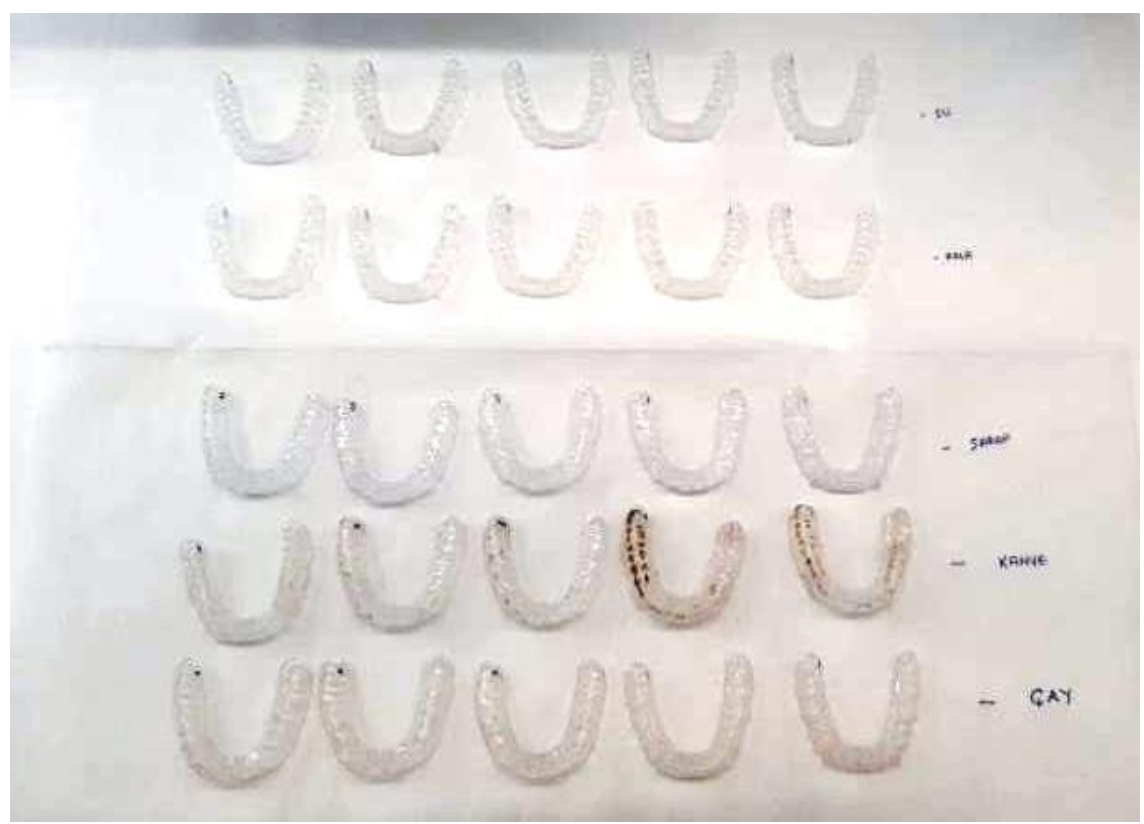


Resim 5. Invisalign marka plakların her bir çözeltide 6 gün boyunca boyanmadan önceki ve sonraki fotoğrafları

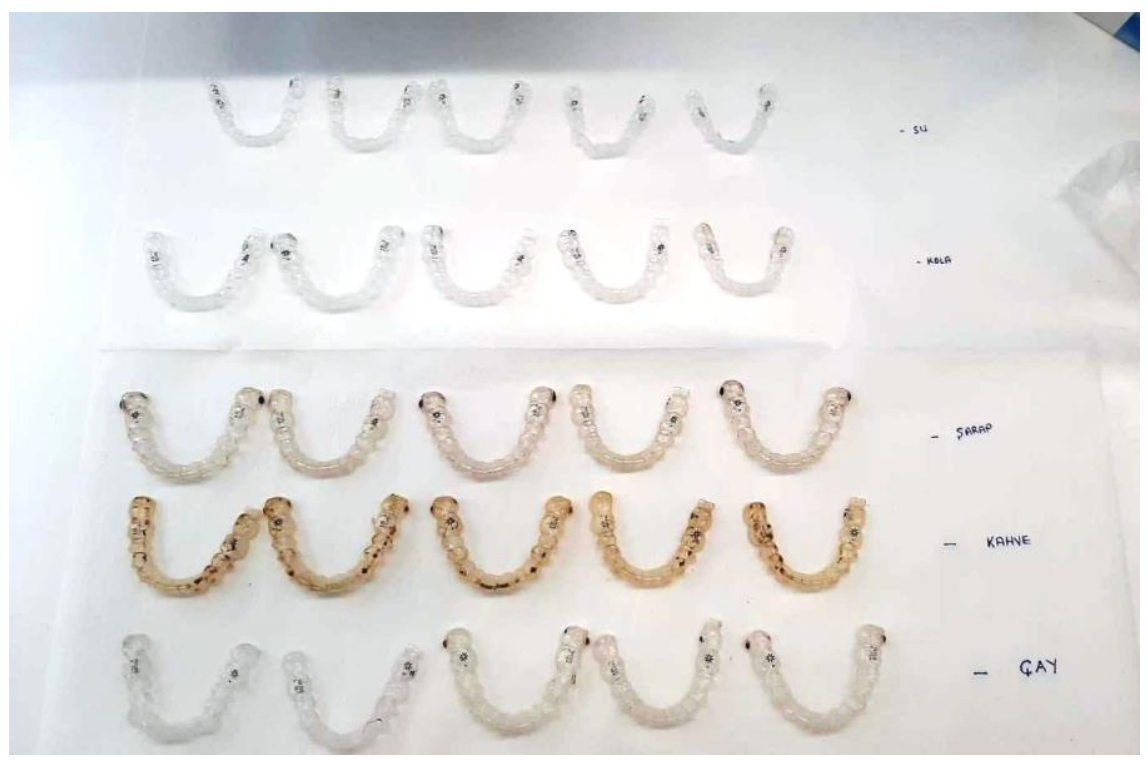

Tablo 2. Plakların To- T1 deki delta e değerleri

\begin{tabular}{|c|c|c|c|c|c|c|c|}
\hline \multicolumn{2}{|l|}{ Grup } & To & T1 & $\begin{array}{l}\text { Ortalama } \\
\text { Fark }\end{array}$ & $\mathbf{t}$ & $\mathbf{p}$ & \\
\hline \multirow{5}{*}{ Invisalign } & Çay & $49.95 \pm 5.13$ & $52.45 \pm 8.63$ & 2.51 & -1.09 & 0.29 & \multirow{5}{*}{$\begin{array}{l}F=1.04 \\
p: 0.32\end{array}$} \\
\hline & Kahve & $49.95 \pm 5.13$ & $49.45 \pm 3.83$ & -0.50 & 0.27 & 0.79 & \\
\hline & Şarap & $49.95 \pm 5.13$ & $54.69 \pm 3.73$ & 4.74 & -2.62 & 0.02 & \\
\hline & Kola & $49.95 \pm 5.13$ & $51.26 \pm 5.23$ & 1.31 & -0.69 & 0.50 & \\
\hline & $\mathrm{Su}$ & $49.95 \pm 5.13$ & $57.79 \pm 4.63$ & 2.84 & -4.70 & 0.01 & \\
\hline \multirow{5}{*}{ Essix } & Çay & $48.01 \pm 6.23$ & $48.00 \pm 7.03$ & -0.01 & 0.01 & 1.00 & \multirow{5}{*}{$\begin{array}{l}\mathrm{F}=0.99 \\
\mathrm{p}: 0.41\end{array}$} \\
\hline & Kahve & $48.01 \pm 6.23$ & $40.41 \pm 5.49$ & -7.61 & 3.98 & 0.01 & \\
\hline & Şarap & $48.01 \pm 6.23$ & $40.60 \pm 3.49$ & -7.41 & 3.48 & 0.01 & \\
\hline & Kola & $48.01 \pm 6.23$ & $52.27 \pm 6.59$ & 4.25 & -1.69 & 0.11 & \\
\hline & $\mathrm{Su}$ & $48.01 \pm 6.23$ & $47.90 \pm 7.38$ & -0.12 & 0.06 & 0.95 & \\
\hline
\end{tabular}

t:Paired Sample t test F:One Way Anova

Tablo 2 incelendiğinde çay, kahve ve kolada bekletilmiş Invisalign plakların To ve T1 ölçüm değerleri arasında istatistiksel olarak anlamlı bir fark göstermemektedir ( $p>0.05$ ). Şarapta bekletilen Invisalign grup plakların To ve T1 ölçüm değerleri arasında istatistiksel olarak anlamlı bir fark bulunmuştur [t(14)=-2.62 p<0.05]. Ortalama değerlere bakıldığında To değerlerinin

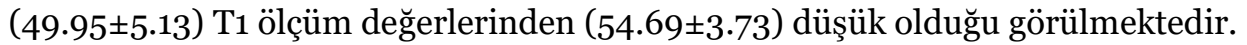

Essix grubu plakların çay, kola ve suda bekletilmiş To ve T1 değerleri arasında istatistiksel olarak anlamlı bir fark göstermemektedir (p>0.05). Kahvede bekletilen Essix marka plakların To ve T1 değerleri arasında istatistiksel olarak anlamlı bir fark bulunmuştur [t(14)=-7.61 p<0.05].

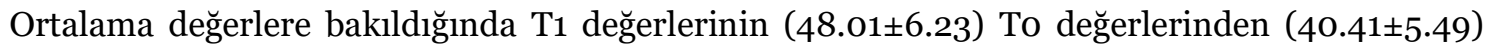
yüksek olduğu görülmektedir. Şarapta bekletilen Essix marka plakların To ve T1 değerleri 
arasında istatistiksel olarak anlamlı bir fark göstermektedir [t(14)=-7.41 $\mathrm{p}<0.05]$. Ortalama değerlere bakıldığında To değerlerinin $(48,01 \pm 6,23)$ T1 değerlerinden $(40.60 \pm 3.49)$ düşük olduğu görülmektedir.

Tablo 3. Invisalign ve Essix markalarının To ve T1 değerlerinin farkı

\begin{tabular}{|l|l|l|l|l|}
\hline & & & $\mathrm{t}$ & $\mathrm{p}$ \\
\hline \multirow{2}{*}{ Çay } & Invisalign & $5.81 \pm 7.03$ & \multirow{2}{*}{-0.20} & \multirow{2}{*}{0.85} \\
\cline { 2 - 3 } & Essix & $6.25 \pm 4.99$ & & \\
\hline \multirow{2}{*}{ Kahve } & Invisalign & $5.84 \pm 3.97$ & \multirow{2}{*}{-1.79} & \multirow{2}{*}{0.08} \\
\cline { 2 - 3 } & Essix & $8.98 \pm 5.52$ & & \\
\hline \multirow{2}{*}{ Şarap } & Invisalign & $7.29 \pm 4.04$ & \multirow{2}{*}{-0.60} & \multirow{2}{*}{0.55} \\
\cline { 2 - 3 } & Essix & $8.54 \pm 6.97$ & & \\
\hline \multirow{2}{*}{ Kola } & Invisalign & $5.98 \pm 4.26$ & \multirow{2}{*}{-1.24} & \multirow{2}{*}{0.22} \\
\cline { 2 - 3 } Su & Essix & $8.39 \pm 6.21$ & & \\
\hline \multirow{2}{*}{ Invisalign } & $8.82 \pm 4.92$ & \multirow{2}{*}{1.83} & \multirow{2}{*}{0.08} \\
\cline { 2 - 3 } & Essix & $5.81 \pm 4.08$ & & \\
\hline
\end{tabular}

To ve T1 değerleri arası farkın çay, kahve, şarap, kola ve suda bekletilen plak türlerine göre istatistiksel olarak anlamlı bir farklılık göstermediği tespit edilmiştir ( $p>0,05$ ) (Tablo 3).

Tablo 4. Invisalign ve Essix termal siklus sonrası yaşlandırma miktarlarının karşılaştırması.

\begin{tabular}{|l|l|l|l|l|}
\hline & & Stndrt Ort & $\mathrm{z}$ & $\mathrm{p}$ \\
\hline \multirow{2}{*}{ Essix } & To & 2.50 & \multirow{2}{*}{$-1.414^{\mathrm{b}}$} & \multirow{2}{*}{0.16} \\
\cline { 2 - 5 } & T1 & 3.13 & & \\
\hline \multirow{2}{*}{ Invisalign } & To & 0.00 & $-2.236^{\mathrm{b}}$ & \multirow{2}{*}{0.03} \\
\cline { 2 - 3 } & T1 & 3.00 & & \\
\hline
\end{tabular}

Z: Wilcoxon Test

Essix marka plaklarda (gram olarak) To ve T1 değerleri arasında istatistiksel olarak anlamlı bir farklılık yoktur ( $\mathrm{p}>0.05$ ). Invisalign marka plaklarda (gram olarak) To ve T1 değerleri arasında istatistiksel olarak anlamlı bir farklılık vardır. (p>0.05) Medyan değerlerine bakıldığında T1 değerlerinin (3.0) To değerlerinden (o) daha yüksek olduğu görülmektedir (Tablo 4).

\section{Tartışma}

Poliüretan malzemeler; yüksek elastikiyet, esneklik, kimyasal direnç, oksidasyon direnci ve işleme kolaylığı gibi çok iyi mekanik özelliklere sahiptir. Yapılan bir çalışmada yapay tükürüğün, düzenli firçalamaya rağmen poliüretan malzemelerde renk değişimini arttırdığı rapor edilmiştir ${ }^{16}$. Plakların mekanik ve kimyasal özellikleri ile ilgili yapılan bir çalışmada, Invisalign apareylerde kullanılan termoplastik poliüretan yüksek sertlik ve elastikiyet modülü gösterse de daha az deformasyon direncine sahip olduğu incelenmiştir ${ }^{13}$.

İşlenmemiş poliüretanın doğal olarak gözenekli bir malzeme olduğu bildirilmiştir ${ }^{1}$. Invisalign şeffaf plakların poliüretanın kutupsal doğası ile birleşen yüzey gözenekliliği, boyanma duyarlılıklarını açıklamaktadır. Şeffaf plaklar oral ortamda bulunmasıyla, zamanla yüzeylerinde 
oluşan; mikro çatlaklar ve konuşma, yutma ve bruksizmden kaynaklanan aşınmalar yüzey pürüzlülüğünü artırabilirr ${ }^{17}$. Yüzeyde oluşan bu bozunmalar pigmentasyonu artırabilmekte ve şeffaflı̆̆ının kaybına yol açabilmektedir. Plakların renk değişiklikleri, plaklar boyama çözeltilerinde bekletildiğinde pigment absorbsiyonu veya çözeltilerin malzeme yüzeyine nüfuz etmesi ile ilişkilendirilmiştir ${ }^{16}$. Bazı araştırmalarda plaklarda oluşan renklenme sonuçlarının farklı çıkmasının nedeni, ajanlardaki boyama pigmentlerinin ve şeffaf plak materyallerinin özellikleri ile ilişkilendirilebilir. Yapılan çalışmalarda plakların renk farklılıkların; içerdikleri farklı polimerlerin, boyar maddelere karşı farklı hassasiyetlere sahip olabileceğini gösterilmiştir ${ }^{14}$.

$\mathrm{Su}$ emilimi, su moleküllerinin materyal yüzeyine bağlanmasından ve emilmesinden kaynaklanmaktadır. Bununla beraber çözeltilerdeki pigmentler de emilmektedir ve malzeme yüzeylerine bağlanmaktadır. ${ }^{17}$ Plak yüzeylerinin pürüzlü olmasının da pigment birikimini hızlandıracağı çalışmalar tarafından gösterilmiştir. Şeffaf plakların çözeltilerde bekletilmesi sonucu plak yüzeyinde oluşan renklenmeler, bu mekanizma ile açlklanabilir.

Çalışmamızda Invisalign grubunda çay, kahve, su ve kolada bekletilmiş plakların To ve T1 değerleri arasında istatistiksel olarak anlamlı bir fark görülmemiştir. Şarapta bekletilen plakların To ve T1 değerleri arasında istatistiksel olarak anlamlı bir fark görülmüştür.

Yapılan bir başka çalışmada, Chen-Liu ve ark. Invisalign ve iki diğer şeffaf plağı (Angelalign ve Smartee) 12 saat ve 7 gün süreyle kahve, siyah çay, kırmızı şarap sıvlarına bekletmişler ve çalışmanın sonucunda sadece Invisalign grubunda kahvede anlamlı bir fark bulunmuştur ${ }^{18}$. Chen-Liu Invisalign grubu plaklarda suda herhangi bir fark tespit edememesine rağmen bizim çalışmamızda su, istatistiksel olarak anlamlı kabul edilmiştir. Yapılan bazı çalışmalarda; poliüretan tabanlı Invisalign plaklar, PC ve PETG tabanlı hizalayıcılardan önemli ölçüde daha yüksek renk değişim değerleri sergilemiştir ${ }^{16}$. Benzer şekilde, önceki çalışmalar poliüretanın pigment absorbsiyonuna karşı savunmasız olduğunu ve genellikle yeterli renk stabilitesi sağlamadığını göstermiş̧tir ${ }^{19}$. Poliüretan bazlı ortodontik tutucular, içeceklere bekletildikten sonra gözle görülür renk değişiklikleri sergilemektedirler.

Essix; termoplastik sınıfında incelenen polimer yapısına sahiptir. Termoplastik materyaller; isı ve basınç altında akışkan kıvama geçip şekil alan, soğutulduğunda katılaşan plastiklerdir. $\mathrm{Bu}$ işlemler sırasında kimyasal değişikliğe uğramazlar. Polimer dalları birbirlerine zayıf fiziksel bağlarla bağlanır ve materyalin ısıtılması bu bağların kopması ile sonuçlanarak kıvamını akışkan hale getirir. Soğutulduğunda bu bağların yeniden oluşması ile materyal katılaşır ${ }^{16}$.

Çalışmamızda; Essix grup şeffaf plaklar çay, kahve, kola, kırmızı şarap ve suda 6 gün süreyle bekletilmiştir. Çay, su ve kolada bekletilmiş plakların To ve T1 değerleri arasında istatistiksel olarak anlamlı bir fark görülmemiştir. Şarapta ve kahvede bekletilen plakların To ve T1 değerleri arasında istatistiksel olarak anlamlı bir fark görülmüştür. Porojan ve ark. şeffaf plaklarda renklenme ve temizleme yöntemlerini incelemek amacıyla 3 farklı termoplastik plak ve renklendirme ajanı olarak çay, kola, kahve ve kontrol çözeltisi kullanarak yaptığı çalışmada, 48. saatin sonunda plaklarda anlamlı renk değişikliği kaydetmişlerdir ${ }^{14}$. Bu çalışmada da gösterildiği üzere, plaklardaki renk değişiklikleri, pürüzlülük gibi yüzey özelliklerine bağlı olabilir fakat Porojan ve ark. plakların yüzey pürüzlülüğü ile renklenme arasında zayıf bir ilişki olduğunu göstermişlerdir ${ }^{14}$.

Çalışmamızda; Invisalign ve Essix marka plakların To ve $\mathrm{T} 1$ sonuçları genel olarak karşılaştırıldığında değerler arası farkın istatistiksel olarak anlamlı bir farklılık göstermediği tespit edilmiştir. Literatürde bizim çalışmamızdan farklı olarak Invisalign grubunda, Essix’ e göre kırmızı şarapta daha fazla renklenme gözlenmiştir. Literatürde, Invisalign daha fazla 
renklenmesini, plakların yüzey gözenekliliğine, bu nedenle Essix hizalayıcılarına kıyasla boyama duyarlılıklarının daha fazla olmasına bağlamışlardır ${ }^{20}$. Çalışmamızda; literatürdeki çalışmaya kıyasla Invisalign plaklarda şarabın Essix'e kıyasla daha fazla renklendirmesi sıvının ve plak türlerinin aynı olması nedeniyle aradaki gün farkına (6 gün-7 gün) bağlanmıştır²1.

Plakların içerdiği PET-G materyallerinin higroskopik bir genleşme ile yüksek su emici polimerler olduğu bilinmektedir ${ }^{14}$. Su emme işleminin, suyun polimer zincirlerinin arasında reaksiyona girerek polimer malzemelerde değişiklikler yarattığı, polimerin kristal fraksiyonlarının da su ilavesinden etkilendiği sonucuna varan çalışmalar mevcuttur ${ }^{22}$.

Tamburrino ve ark. termoplastik materyallerin mekanik özelliklerini incelemek için 3 farklı termoplastik şeffaf plak (Duran, Biolon, Zendura) ile yaptığı çalışmada; sıvı emiliminin plak boyutunu etkileyerek arkta uyum problemi yaşanabileceğini rapor etmişlerdir ${ }^{17}$. Bu durumda dişlere uygulanan ortodontik kuvvetin etkinliğinde kayıp yaşanabileceğini belirtmişlerdir. Bizim çalışmamızda da Invisalign plakların termal siklus sonrası su emme miktarı anlamlı kabul edilmektedir. Şeffaf plakların üretimi sırasında, PETG'ye poliüretan eklendiğinde su emiliminin arttığını bildirmiştir ${ }^{23}$. Bu bilgiye dayanarak Invisalign marka plakların su emiliminin, Essix marka şeffaf plaklara göre daha fazla olmasının sebebi açıllanabilir.

Zhang ve ark. termoplastik plakların su emilimini incelemek amacıyla yaptı̆̆ termal vakumla farklı kalınlıklarda dört tip termoplastik malzeme kullanmıştır ve termoform işleminden sonra tüm malzemelerin su emme kabiliyetinin arttı̆̆ını göstermişlerdir ${ }^{20}$.

\section{Limitasyonlar}

Çalışmamızda herhangi bir finansman desteği kullanılmamış olup, Invisalign grubunda kullanılacak plaklar, Invisalign firmasından plak talep edilerek planlanmıştır. Grup sayısının fazla olması nedeniyle her bir grupta 5 adet plak değerlendirilmiştir. Sonraki çalışmalarda power analizi yapılarak daha kapsamlı değerlendirmelere yapılabilir.

Literatürde çay ve kahvede bekletilen çalışmalarda ${ }^{21,24}$ standardizasyon için örnekler $37^{\circ} \mathrm{C}^{\prime} \mathrm{de}$ bekletilmiş olsa da tüketilen sıvıların sıcaklığı tam değerini yansıtmamaktadır. Bu durum gelecek çalışmalarda göz önünde bulundurulmalıdır.

\section{Sonuç}

Invisalign grubunda şarap istatistiksel olarak anlamlı değişim olmasına karşın, Essix grubunda kahve ve şarapta anlaml şekilde renklenme kaydedilmiştir. Her iki plak birbirleri ile kıyaslandığında renklenmede anlamlı bir fark görülmemiştir. Invisalign grubundaki plaklarda (gram olarak) istatistiksel olarak anlamlı bir fark görülmüştür.

Şeffaf plak kullanan hastalar termoplastik malzemede oluşabilecek renk değişikliklerini önlemek amacıyla içecek tüketimleri sırasında plaklarını çıkarmalıdır.

\section{KAYNAKLAR}

1. Jindal P, Juneja M, Siena FL, Bajaj D, Breedon P. Mechanical and geometric properties of thermoformed and 3D printed clear dental aligners. Am J Orthod Dentofacial Orthop. Nov 2019;156(5):694-701. doi:10.1016/j.ajodo.2019.05.012.

2. Aksoy FA. Şeffaf Plaklar ile Çekimli Ortodontik Tedavi. [bitirme tezi].İstanbul, Türkiye:Diş Hekimliği Fakültesi, İstanbul Üniversitesi; 2020.

3. Melkos AB. Advances in digital technology and orthodontics: a reference to the Invisalign method. Med Sci Monit. 2005;11(5):PI39-42. 
4. Pruzansky DP, Park JH. Quality of lab appliances in orthodontic offices. J Clin Pediatr Dent. 2016;40(6):506-509. doi:10.17796/1053-4628-40.6.506.

5. Johal A, Bondemark L. Clear aligner orthodontic treatment: Angle Society of Europe consensus viewpoint. J Orthod. 2021;48(3):300-304. doi:10.1177/14653125211006423.

6. Papadimitriou A, Mousoulea S, Gkantidis N, Kloukos D. Clinical effectiveness of Invisalign orthodontic treatment: A systematic review. Prog Orthod. 2018;19(1):37. doi:10.1186/s40510-018-0235-z.

7. Weir T. Clear aligners in orthodontic treatment. Aust Dent J. 2017;62 Suppl 1:58-62. doi:10.1111/adj.12480.

8. Lu H, Tang H, Zhou T, Kang N. Assessment of the periodontal health status in patients undergoing orthodontic treatment with fixed appliances and invisalign system: A metaanalysis. Medicine (Baltimore). 2018;97(13):e0248. doi:10.1097/MD.0000000000010248.

9. Papadopoulou AK, Cantele A, Polychronis G, Zinelis S, Eliades T. Changes in roughness and mechanical properties of invisalign. Materials (Basel). 2019;12(15). doi:10.3390/ma12152406.

10. Schuster S, Eliades G, Zinelis S, Eliades T, Bradley TG. Structural conformation and leaching from in vitro aged and retrieved invisalign appliances. Am J Orthod Dentofacial Orthop. 2004;126(6):725-8. doi:10.1016/j.ajodo.2004.04.021.

11. Ercoli F, Tepedino M, Parziale V, Luzi C. A comparative study of two different clear aligner systems. Prog Orthod. 2014;15(1):31. doi:10.1186/s40510-014-0031-3.

12. Living with Invisalign $®$ clear aligners. https://www.invisalign.com/how-invisalignworks/living-with-invisalign. Erişim tarihi 2021.

13. Bucci R, Rongo R, Levatè $\mathrm{C}$, et al. Thickness of orthodontic clear aligners after thermoforming and after 10 days of intraoral exposure: a prospective clinical study. Prog Orthod. 2019;20(1):36. doi:10.1186/s40510-019-0289-6.

14. Porojan L, Vasiliu RD, Porojan SD, Bîrdeanu MI. Surface Quality evaluation of removable thermoplastic dental appliances related to staining beverages and cleaning agents. Polymers (Basel). 2020;12(8). doi:10.3390/polym12081736.

15. Miller KB, McGorray SP, Womack R, et al. A comparison of treatment impacts between Invisalign aligner and fixed appliance therapy during the first week of treatment. Am J Orthod Dentofacial Orthop. 2007;131(3):302.e1-9. doi:10.1016/j.ajodo.2006.05.031.

16. Alexandropoulos A, Al Jabbari YS, Zinelis S, Eliades T. Chemical and mechanical characteristics of contemporary thermoplastic orthodontic materials. Aust Orthod J. Nov 2015;31(2):165-70.

17. Tamburrino F, D'Antò V, Bucci R, Alessandri-Bonetti G, Barone S, Razionale AV. Mechanical Properties of Thermoplastic Polymers for Aligner Manufacturing: In Vitro Study. Dent J (Basel). 2020;8(2). doi:10.3390/dj8020047.

18. Liu Y. Advantages and disadvantages of clear aligner treatment in orthodontics. eds Zhonghua Kou Qiang Yi Xue Za Zhi. Sep o9 2017;52(9):538-542. doi:10.3760/cma.j.issn.1002-0098.2017.09.005.

19. Milovanović A, Sedmak A, Golubović Z, et al. The effect of time on mechanical properties of biocompatible photopolymer resins used for fabrication of clear dental aligners. $J$ Mech Behav Biomed Mater. 2021;119:104494. doi:10.1016/j.jmbbm.2021.104494.

20. Zhang N, Bai Y, Ding X, Zhang Y. Preparation and characterization of thermoplastic materials for invisible orthodontics. Dent Mater J. 2011;30(6):954-9. doi:10.4012/dmj.2011-120. 
21. Liu CL, Sun WT, Liao W, et al. Colour stabilities of three types of orthodontic clear aligners exposed to staining agents. Int J Oral Sci. 1216 2016;8(4):246-253.

doi:10.1038/ijos.2016.25.

22. Ryu JH, Kwon JS, Jiang HB, Cha JY, Kim KM. Effects of thermoforming on the physical and mechanical properties of thermoplastic materials for transparent orthodontic aligners. Korean J Orthod. 2018;48(5):316-325. doi:10.4041/kjod.2018.48.5.316.

23. Lombardo L, Arreghini A, Maccarrone R, Bianchi A, Scalia S, Siciliani G. Optical properties of orthodontic aligners-spectrophotometry analysis of three types before and after aging. Prog Orthod. 2015;16:41. doi:10.1186/s40510-015-0111-z.

24. Bernard G, Rompré P, Tavares JR, Montpetit A. Colorimetric and spectrophotometric measurements of orthodontic thermoplastic aligners exposed to various staining sources and cleaning methods. Head Face Med. Feb 18 2020;16(1):2. doi:10.1186/s13005-020o0218-2. 